\title{
Economic burden of HPV9-related diseases: a real-world cost analysis from Italy
}

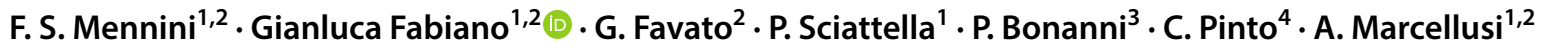

Received: 17 April 2018 / Accepted: 14 March 2019

๑) Springer-Verlag GmbH Germany, part of Springer Nature 2019

\begin{abstract}
Introduction The objectives of this study were to estimate the economic burden of HPV in Italy, accounting for total direct medical costs associated with nine major HPV-related diseases, and to provide a measure of the burden attributable to HPV $6,11,16,18,31,33,45,52,58$ infections.

Methods A cost-of-illness incidence-based model was developed to estimate the incidences and costs of invasive cervical cancer, cervical dysplasia, cancer of the vulva, vagina, anus, penis, oropharyngeal, anogenital warts, and recurrent respiratory papillomatosis (RRP) in the context of the Italian National Health System (NHS). We used data from hospital discharge records (HDRs) of an Italian region and conducted a systematic literature review to estimate the lifetime cost per case, the number of incident cases, the prevalence of HPV9 types. Costs of therapeutic options not included in the diagnosis-related group (DRG) tariffs were estimated through a scenario analysis.

Results In 2018, the total annual direct costs were $€ 542.7$ million, with a range of $€ 346.7-€ 782.0$ million. These costs could increase considering innovative therapies for cancer treatment (range $€ 16.2-€ 37.5$ million). The fraction attributable to the HPV9 genotypes without innovative cancers treatment was $€ 329.5$ million, accounting for $61 \%$ of the total annual burden of HPV-related diseases in Italy. Of this amount, $€ 135.9$ million (41\%) was related to men, accounting for $64 \%$ of the costs associated with non-cervical conditions.

Conclusions The infections by HPV9 strains and the economic burden of non-cervical HPV-related diseases in men were found to be the main drivers of direct costs.
\end{abstract}

Keywords Burden of disease $\cdot$ Human papillomavirus $\cdot$ Real world $\cdot$ Italy

Electronic supplementary material The online version of this article (https://doi.org/10.1007/s10198-019-01044-3) contains supplementary material, which is available to authorized users.

Gianluca Fabiano

g.fabiano@kingston.ac.uk

1 Economic Evaluation and HTA (EEHTA)-CEIS, Faculty of Economics, University of Rome "Tor Vergata”, Rome, Italy

2 Institute for Leadership and Management in Health, Kingston University, London, UK

3 Department of Health Sciences, University of Florence, Florence, Italy

4 Medical Oncology Unit, Clinical Cancer Centre, AUSL-IRCCS of Reggio Emilia, Reggio Emilia, Italy

\section{Introduction}

Human papillomavirus (HPV) is the most common sexually transmitted virus and causes a substantial burden of disease in both men and women [1]. The prevalence of HPV remains unacceptably high. In 2013-2014, approximately $45 \%$ of men and $40 \%$ of women between the ages of 18 and 59 had genital HPV infection [2]. Genital HPV infections are contracted through unprotected vaginal or anal sexual intercourse and skin-to-skin genital contact. HPV infections that result in oral or upper respiratory malignancies are mostly contracted through unprotected oral sex [3]. Most HPV infections are asymptomatic and resolve within a few months of exposure. However, the infection can progress to form pre-cancerous and cancerous lesions. HPV has been shown to be the cause of several clinically significant conditions. As of this writing, more than 100 types of papillomavirus strains that can infect humans have been identified. These 
have been divided into high- and low-risk types according to their risk of progressing to cancer. The high-risk oncogenic variants of HPV, specifically genotypes 16 and 18 , account for approximately $70 \%$ of all cases of invasive cervical cancer and cervical dysplasia worldwide $[4,5]$. They also account for a smaller fraction of cancers of the vulva, vagina, anus, penis, head and neck [6]. The low-risk HPV variants of genotypes 6 and 11 are responsible for approximately $90 \%$ of benign external anogenital warts [7] and almost all cases of recurrent respiratory papillomatosis (RRP) $[8,9]$.

Primary prevention of HPV-related diseases is possible with vaccination. Three vaccines (Cervarix, Gardasil and Gardasi19) are currently approved for the prevention of HPV infection. All of these vaccines are active against the highrisk HPV 16 and 18 strains, while Gardasil ${ }^{\circledR}$ also protects against HPV 6 and 11. Gardasil9 was authorized in the European market in 2015 and protects against nine strains of HPV, including types $6,11,16,18,31,33,45,52$, and $58[10,11]$. The availability of these vaccines has led to the initiation of population-wide immunization programmes in most western countries. Based on previous cost-effectiveness studies, the primary aim of most HPV immunization programmes has been to protect women against cervical cancer [12-14]. However, a study published in 2012 demonstrated the relevance of the burden of HPV malignancies in men to all who pay for healthcare services (the Italian National Health System, NHS) [15]. A subsequent study demonstrated the cost-effectiveness of gender-neutral immunization in Italy [14]. Based on these findings, in 2017, the Italian Government became the first of the G9 countries to introduce a universal, recommended and free vaccination for HPV for girls and boys at the age of 12 [16].

Because of these policy changes, the aim of the study was to provide an estimate of the total, direct medical costs attributable to HPV infection, with stratification of the burden by sex as well as specific diseases using cost inputs taken from the Italian National Health Service. Furthermore, this study also calculated an aggregate measure of the total economic burden attributable to HPV 6, 11, 16, 18, 31, 33, 45,52 and 58 infections as an estimate of the potential savings due to the introduction of the nine-valent universal HPV vaccination programme.

\section{Methods}

\section{Study design}

The study design was developed using the Italian National Health Service (NHS), from which the cost inputs were selected. A systematic review of the literature was conducted to identify economic and epidemiological data related to each HPV-induced disease. The review was aimed to identify the best secondary data available to produce lifetime costs per case estimates. In particular we searched for epidemiological data such as incidence and prevalence rates as well as direct cost estimates from the perspective of the Italian national payer. As a result, lifetime costs for cervical dysplasia, anogenital warts and cervical cancer were modelled based on a number of previously published studies (Table 1) [17]. Due to the lack of available information regarding RRP in the Italian context, treatment assumptions were speculated for this disease on the basis of international literature as well as tariffs applied by Italian diagnosis-related groups (DRGs).

Real-world data were used to estimate hospital-based management costs of the main HPV-induced malignancies: cervical, vulvar, vaginal, penile, head and neck cancer. Specifically, hospital discharge records (HDRs) from 2010 to 2014 from the administrative archives of the Marche region were analysed to identify hospitalization rates as well as the costs associated with HPV-related diseases. This approach was followed and validated by previous publications made in this field [24]. Finally, outpatient costs related to these malignancies were estimated based on the latest national tariffs (2013) for specialist consultation procedures, and treatment paradigms were validated by the expert opinions of a group of clinicians. An incidence-based approach was then adopted to estimate lifetime costs per case and produce an aggregate measure of the economic burden. The relative prevalence rates of HPV types $6,11,16,18,31,33,45,52$, and 58 according to the literature were applied to estimate the aggregate fraction of costs attributable to HPV infections in Italy.

\section{Real-world data analysis}

Information related to the hospital discharges (HDRs) of all accredited public and private hospitals in the Marche Region, both for ordinary and day-care regimens, were included to estimate the costs of cervical, vulvar, vaginal, penile, head and neck cancer. The total costs related to hospitalizations were calculated using the DRGs (with 2013 values) of hospitalized patients based on their age, gender and their consumption of resources during their hospital stay. The DRG system aggregates all activities, including surgical interventions, administered drugs, expended materials and personnel for each individual diagnosis and stipulates the reimbursement tariff. This value corresponds to the total amount of all interventions provided that is to be paid to the hospital. According to the DRG-based reimbursement system, every hospitalized patient was assigned to a group of diagnostically homogeneous cases; therefore, patients with the same DRG values were assigned the same reimbursement charges.

We included hospitalizations of patients who were residents of the Marche region, were older than 18 years of 
Table 1 Estimates of lifetime cost per patient by diagnosis

\begin{tabular}{|c|c|c|c|c|c|}
\hline Diagnoses & $\begin{array}{l}\text { Surgical procedures and medical } \\
\text { treatments }\end{array}$ & $\begin{array}{l}\text { Direct cost per } \\
\text { procedure or medical } \\
\text { treatment } \\
a\end{array}$ & $\begin{array}{l}\text { Compound } \\
\text { inflation rate } \\
(\%) \\
b\end{array}$ & $\begin{array}{l}\text { Lifetime direct cost } \\
\text { per incident patient } \\
\text { (2018 Euro) } \\
a \times b\end{array}$ & Source \\
\hline \multicolumn{6}{|c|}{ Cervical cancer } \\
\hline & Management of primary tumour & $€ 13,122$ & 117.50 & $€ 15,418$ & {$[17]$} \\
\hline & $\begin{array}{l}\text { Discounted cost of progression/ } \\
\text { recurrence after 1 year }\end{array}$ & $€ 8827$ & 117.50 & $€ 10,372$ & {$[17]$} \\
\hline & Lifetime cost per patient & $€ 21,949$ & & $€ 25,790$ & \\
\hline \multicolumn{6}{|c|}{ Cervical dysplasia } \\
\hline & Abnormal PAP smears & $€ 25$ & 117.50 & $€ 29$ & {$[18]$} \\
\hline & Colposcopies & $€ 101$ & 117.50 & $€ 119$ & {$[18]$} \\
\hline & Diagnosis of cervical dysplasia & $€ 34$ & 117.50 & $€ 40$ & [19] \\
\hline & CIN1 treatment & $€ 686$ & 117.50 & $€ 806$ & {$[20]$} \\
\hline & CIN2 treatment & $€ 1242$ & 117.50 & $€ 1459$ & {$[20]$} \\
\hline & CIN3 treatment & $€ 1763$ & 117.50 & $€ 2072$ & {$[20]$} \\
\hline & Lifetime cost per patient & $€ 4011$ & & $€ 4525$ & \\
\hline \multicolumn{6}{|c|}{ Anal cancer (women) } \\
\hline & Tot, lifetime hospitalizations & $€ 9607$ & 109.30 & $€ 10,500$ & $\begin{array}{l}\text { ICD9-CM (154.2-154.3; } \\
154.8)\end{array}$ \\
\hline & $\begin{array}{l}\text { Follow-up } 2 \text { clinical examinations } \\
(\times 3)\end{array}$ & $€ 20.66$ & 102.20 & $€ 42$ & Outpatient tariff (89.7) [21] \\
\hline & Follow-up sector CT scan $(\times 3)$ & $€ 74.88$ & 102.20 & $€ 77$ & Outpatient tariff (87.03) [21] \\
\hline & Follow-up sector CT scan $(\times 3)$ & $€ 77.67$ & 102.20 & $€ 79$ & Outpatient tariff (87.41) [21] \\
\hline & Follow-up sector CT scan $(\times 3)$ & $€ 79.47$ & 102.20 & $€ 81$ & Outpatient tariff (88.01) [21] \\
\hline & Lifetime cost per patient & $€ 9860$ & 3 & $€ 11,570$ & \\
\hline \multicolumn{6}{|c|}{ Anal cancer (men) } \\
\hline & Tot, lifetime hospitalizations & $€ 15,876$ & 109.30 & $€ 17,353$ & $\begin{array}{l}\text { ICD9-CM (154.2-154.3; } \\
154.8)\end{array}$ \\
\hline & $\begin{array}{l}\text { Follow-up } 2 \text { clinical examinations } \\
(\times 3)\end{array}$ & $€ 20.66$ & 102.20 & $€ 42$ & Outpatient tariff (89.7) [21] \\
\hline & Follow-up sector CT scan $(\times 3)$ & $€ 74.88$ & 102.20 & $€ 77$ & Outpatient tariff (87.03) [21] \\
\hline & Follow-up sector CT scan $(\times 3)$ & $€ 77.67$ & 102.20 & $€ 79$ & Outpatient tariff (87.41) [21] \\
\hline & Follow-up sector CT scan $(\times 3)$ & $€ 79.47$ & 102.20 & $€ 81$ & Outpatient tariff (88.01) [21] \\
\hline & Lifetime cost per patient & $€ 16,129$ & 3 & $€ 18,422$ & \\
\hline \multicolumn{6}{|c|}{ Oropharyngeal cancer (women) } \\
\hline & Tot, lifetime hospitalizations & $€ 11,210$ & 109.30 & $€ 12,253$ & ICD9-CM (146.0-146.9) [21] \\
\hline & $\begin{array}{l}\text { Follow-up } 2 \text { clinical examinations } \\
(\times 3)\end{array}$ & $€ 20.66$ & 102.20 & $€ 42$ & Outpatient tariff (89.7) [21] \\
\hline & Follow-up sector CT scan $(\times 3)$ & $€ 77.67$ & 102.20 & $€ 79$ & Outpatient tariff (87.41) [21] \\
\hline & Follow-up sector CT scan $(\times 3)$ & $€ 79.47$ & 102.20 & $€ 81$ & Outpatient tariff (88.01) [21] \\
\hline & Lifetime cost per patient & $€ 11,388$ & 3 & $€ 13,029$ & \\
\hline \multicolumn{6}{|c|}{ Oropharyngeal cancer (men) } \\
\hline & Tot, lifetime hospitalizations & $€ 23,096$ & 109.30 & $€ 25,244$ & ICD9-CM (146.0-146.9) \\
\hline & $\begin{array}{l}\text { Follow-up } 2 \text { clinical examinations } \\
(\times 3)\end{array}$ & $€ 20.66$ & 102.20 & $€ 42$ & Outpatient tariff (89.7) [21] \\
\hline & Follow-up sector CT scan $(\times 3)$ & $€ 77.67$ & 102.20 & $€ 79$ & Outpatient tariff (87.41) [21] \\
\hline & Follow-up sector CT scan $(\times 3)$ & $€ 79.47$ & 102.20 & $€ 81$ & Outpatient tariff (88.01) [21] \\
\hline & Lifetime cost per patient & $€ 23,274$ & 3 & $€ 26,021$ & \\
\hline \multicolumn{6}{|c|}{ Vulvar and vaginal cancer } \\
\hline & Tot, lifetime hospitalizations & $€ 11,084$ & 109.30 & $€ 12,115$ & $\begin{array}{l}\text { ICD9-CM (184.0-184.4; } \\
\text { 184.8-184.9) }\end{array}$ \\
\hline
\end{tabular}


Table 1 (continued)

\begin{tabular}{|c|c|c|c|c|c|}
\hline \multirow[t]{5}{*}{ Diagnoses } & $\begin{array}{l}\text { Surgical procedures and medical } \\
\text { treatments }\end{array}$ & $\begin{array}{l}\text { Direct cost per } \\
\text { procedure or medical } \\
\text { treatment } \\
a\end{array}$ & $\begin{array}{l}\text { Compound } \\
\text { inflation rate } \\
(\%) \\
b\end{array}$ & $\begin{array}{l}\text { Lifetime direct cost } \\
\text { per incident patient } \\
\text { (2018 Euro) } \\
a \times b\end{array}$ & Source \\
\hline & $\begin{array}{l}\text { Follow-up } 2 \text { clinical examinations } \\
(\times 3)\end{array}$ & $€ 20.66$ & 102.20 & $€ 42$ & Outpatient tariff (89.26) [21] \\
\hline & Follow-up sector CT scan $(\times 3)$ & $€ 77.67$ & 102.20 & $€ 79$ & Outpatient tariff (87.41) [21] \\
\hline & Follow-up sector CT scan $(\times 3)$ & $€ 79.47$ & 102.20 & $€ 81$ & Outpatient tariff (88.01) [21] \\
\hline & Lifetime cost per patient & $€ 11,262$ & 3 & $€ 12,890$ & \\
\hline \multicolumn{6}{|c|}{ Penile cancer } \\
\hline & Tot, lifetime hospitalizations & $€ 7031$ & 109.30 & $€ 7685$ & ICD9-CM (187.1-187.9) \\
\hline & $\begin{array}{l}\text { Follow-up } 2 \text { clinical examinations } \\
(\times 3)\end{array}$ & $€ 20.66$ & 102.20 & $€ 42$ & Outpatient tariff (89.7) [21] \\
\hline & Follow-up sector CT scan $(\times 3)$ & $€ 77.67$ & 102.20 & $€ 79$ & Outpatient tariff (87.41) [21] \\
\hline & Follow-up sector CT scan $(\times 3)$ & $€ 79.47$ & 102.20 & $€ 81$ & Outpatient tariff (88.01) [21] \\
\hline & Lifetime cost per patient & $€ 7209$ & 3 & $€ 8461$ & \\
\hline \multicolumn{6}{|c|}{ Anogenital warts (women) } \\
\hline & $\begin{array}{l}\text { Direct outpatient costs for new } \\
\text { patients }\end{array}$ & $€ 368$ & 119.80 & $€ 441$ & {$[22]$} \\
\hline & $\begin{array}{l}\text { Discounted cost of recurrence } \\
\text { after } 1 \text { year }(50.6 \% \text { prob })\end{array}$ & $€ 176$ & 119.80 & $€ 211$ & {$[22]$} \\
\hline & $\begin{array}{l}\text { Discounted cost of resistance } \\
\text { after } 1 \text { year }(28.2 \% \text { prob })\end{array}$ & $€ 43$ & 119.80 & $€ 52$ & {$[22]$} \\
\hline & Lifetime cost per patient & $€ 587$ & & $€ 703$ & \\
\hline \multicolumn{6}{|c|}{ Anogenital warts (men) } \\
\hline & $\begin{array}{l}\text { Direct outpatient costs for new } \\
\text { patients }\end{array}$ & $€ 275$ & 119.80 & $€ 329$ & {$[22]$} \\
\hline & $\begin{array}{l}\text { Discounted cost of recurrence } \\
\text { after } 1 \text { year }(34.8 \% \text { prob })\end{array}$ & $€ 59$ & 119.80 & $€ 71$ & {$[22]$} \\
\hline & $\begin{array}{l}\text { Discounted cost of resistance } \\
\text { after } 1 \text { year }(38.5 \% \text { prob) }\end{array}$ & $€ 82$ & 119.80 & $€ 98$ & {$[22]$} \\
\hline & Lifetime cost per patient & $€ 416$ & & $€ 498$ & \\
\hline \multicolumn{6}{|l|}{ RRP } \\
\hline & $\begin{array}{l}\text { Management of complicated } \\
\text { throat infection }\end{array}$ & $€ 5744$ & 102.20 & $€ 5870$ & DRG 79 \\
\hline & $\begin{array}{l}\text { Acute clinical treatment of throat } \\
\text { infection }(\times 3)\end{array}$ & $€ 9650$ & 102.20 & $€ 29,587$ & DRG 76 \\
\hline & Minor throat surgery $(\times 4.4)$ & $€ 4378$ & 102.20 & $€ 19,687$ & DRG 63 \\
\hline & Tracheostomy (11\% rate) & $€ 8737$ & 102.20 & $€ 982$ & DRG 75 \\
\hline & Annual cost per patient & $€ 28,509$ & & $€ 56,126$ & \\
\hline & Lifetime cost per patient & & 3 & $€ 224,860$ & \\
\hline
\end{tabular}

$C I N$ cervical intra-epithelial neoplasia, $R R P$ recurrent respiratory papillomatosis, $C T$ computed tomography, Tot total, prob probability

${ }^{\mathrm{a}}$ Costs have been adjusted for 2018 inflation values using the compound annual Italian National Consumer Price Indexes [23] from 2005 (119.8\%), 2006 (117.5\%), $2010(109.3 \%)$, and $2013(102.2 \%)$

age, and who presented one of the following codes from the International Classification of Diseases, 9th revisionClinical Modification (ICD-9-CM) as the primary or secondary diagnosis: 'Anal cancers' (154.2-154.8); 'Oropharyngeal cancers' (146.0-146.9); 'Other female genital organs' (184.0-184.9); and 'Penile cancer' (187.1-187.9). A cohort of 810 patients ( $40 \%$ male and $60 \%$ female) who were hospitalized in 2010 or 2011 was selected from those who did not fall into any of the reported ICD9-CM diagnosis categories and who had not had other malignant tumours in the 2 years prior to their first hospital admission (naïve). Subjects were included and then followed for 3 years after their first hospital admission. Based on expert opinions and [15], we assumed that a 3-year period was appropriate in terms of resource utilization to estimate lifetime costs. In addition, outpatient visits were modelled based on the clinical 
pathway followed by [21] which was validated here by the clinical experts involved in the study. In particular based on the clinical guidelines and current practices, a number of procedures per each diagnose was established to represent the amount of outpatient services provided to patients lifetime. Outpatient costs were then applied based on the 2013 national tariffs for specialists' office consultations and procedures [15].

\section{Literature review}

Secondary data were identified through a systematic literature review. The search was carried out according to the Preferred Reporting Items for Systematic Reviews and MetaAnalyses (PRISMA) guidelines [25] (Fig. 1). The search was conducted in October 2017 and covered the period 1990-2017. The analysis was performed through the online MEDLINE (Medical Literature Analysis and Retrieval System) bibliographic archive of MEDLARS using the PubMed search system and EMBASE accessed through OVID SP. To retrieve robust data that were relevant to Italy, the inquiry was integrated with grey literature obtained from generic academic search engines (e.g., Google Scholar) and websites such as the Italian Ministry of Health, the Italian National Institute of Health (NIH), and those of Italian scientific societies such as the Italian Society of Health Technology Assessment (SIHTA). The search keys used to conduct the literature are reported in Annex B.

\section{Screening and data extraction}

Two independent researchers screened the titles and abstracts. Full-text articles were included if they met the following inclusion criteria: (1) they reported epidemiological data (incident cases by disease and the prevalence of HPV by genotype) derived from population databases, such as national surveys or registries; and (2) they reported direct cost data from the perspective of the payer and expressed monetary values for hospital DRGs and outpatient tariffs. Studies were also required to contain estimates of reported lifetime costs or appropriate data to estimate these costs. For all phases of the literature review, disagreements were
Fig. 1 Literature review, PRISMA

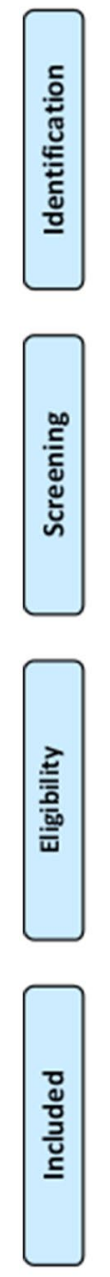

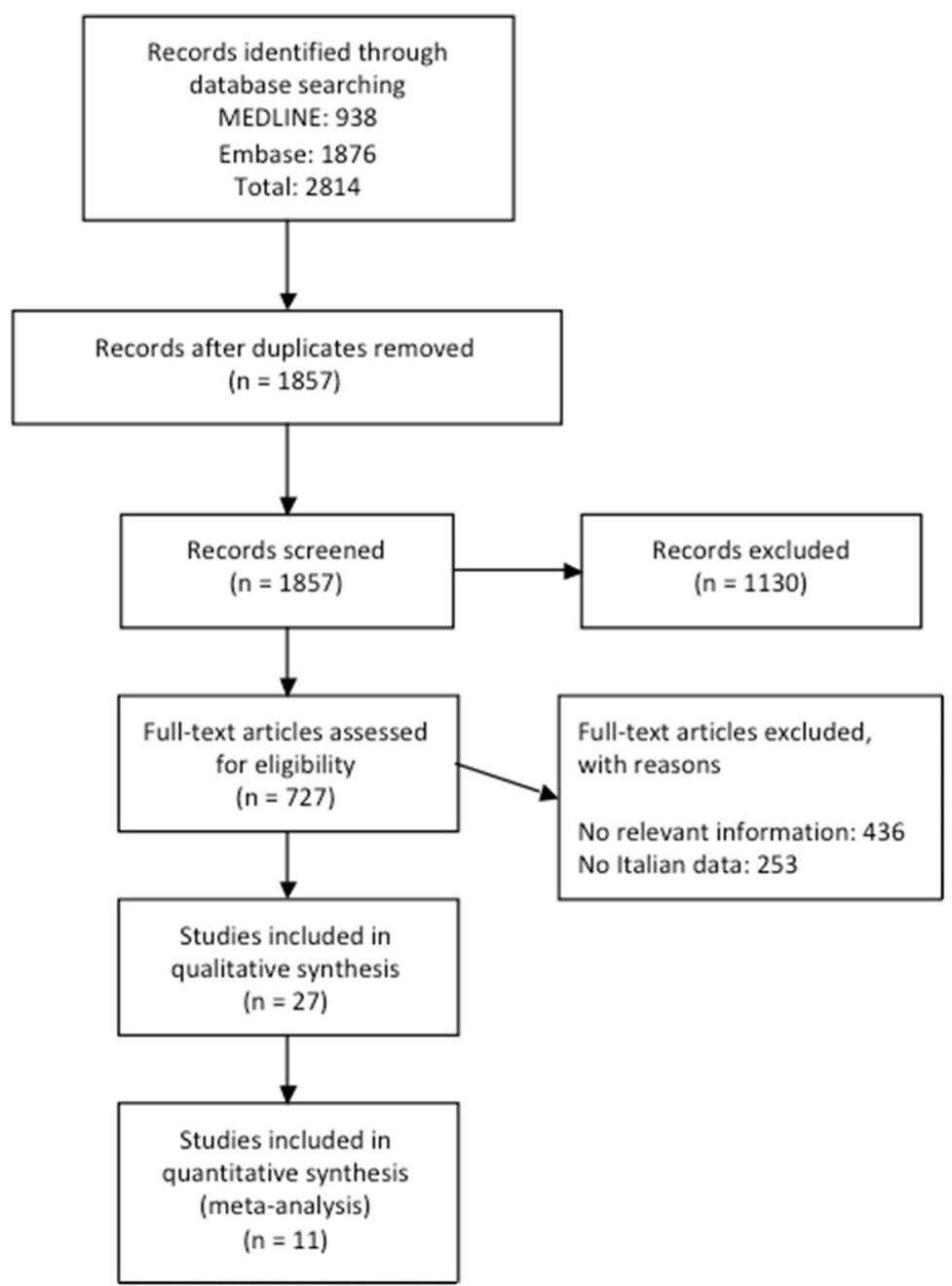


resolved by discussions among the entire team to reach a consensus.

\section{Lifetime costs}

An incidence-based approach was adopted in which the lifetime costs per case associated with each condition were applied to the estimated number of incident cases that were attributable to HPV. We sought to develop cost-per-case estimates that represented the current values of the total direct medical costs accrued from the time of diagnosis to the end of follow-up (Table 1).

Specifically, cost estimates for cervical cancer were obtained from a published Italian study [17] that estimated the mean total direct costs for cervical cancer, including those generated by the management of disease progression and recurrence. The actual costs were not reported, although the median follow-up duration of the cohort was 23 months (range 1-89). We assumed that the mean cost per patient for primary tumour treatment $(€ 13,122)$ was incurred within year 1 , whereas the mean cost associated with the management of disease progression and recurrence (€9092) was incurred in the following year, and we reduced this secondyear value by 3\% (€8827). The selected discount rate (3\%) reflects the opportunity costs of financing from the perspective of a public payer (the Italian NHS) according to Italian AIES (Italian Health Economics Association) guidelines [26].

Lifetime costs associated with the clinical and surgical management of cervical dysplasia were estimated from published Italian data $[18,19]$.

The lifetime cost per patient of non-cervical malignancies was modelled on the national treatment guidelines of a previously published study [15]. Therefore, in addition to the real-world data used to estimate the lifetime costs of hospitalization, we also included two clinical examinations conducted by specialists and two two-sector computed tomography (CT) scans per year. These costs were then reported over a 3-year follow-up period, which is consistent with the realworld data according to [15] and expert opinion. Outpatient fees were attributed to each surgical procedure and medical treatment using national outpatient tariff values (2013). Hospitalization costs (including outpatient costs) incurred after the first 12 months of treatment were discounted at a rate of $3 \%$ per year to obtain their current net value expressed in the value of the Euro in 2013.

The estimated lifetime cost of anogenital warts per incident case was calculated as the sum of the mean, inflationadjusted direct costs incurred by new patients ( $€ 416$ for women and $€ 311$ for men) and the probable, discounted, inflation-adjusted mean direct costs of recurrent ( $€ 199$ for women and $€ 66$ for men) and resistant ( $€ 48$ for women and $€ 92$ for men) episodes observed over 1 year after initial diagnosis. These figures were modelled on a previously published article [22]. Probability rates were calculated based on the number of recurrent $(50.6 \%$ for women and $34.8 \%$ for men) and resistant (28.2\% for women and $38.5 \%$ for men) cases reported as a percentage of the annual number of newly diagnosed cases, assuming a steady state in the total number of genital warts treated in Italy [22].

Finally, to estimate the lifetime cost per RRP patient, elective surgical procedures and medical treatments were selected according to published reports from the US [27, 28]. Treatment assumptions included the management of complicated respiratory infections, three acute clinical treatments, 4.4 surgical procedures, and a tracheotomy rate of $11 \%$ per year [27]. Italian DRG tariffs for 2013 were applied to the selected procedures. The duration of the disease was estimated to be 4.2 years [27]. All costs incurred after the first 12 months of treatment were discounted at a rate of $3 \%$ per year to obtain their current net value expressed in the value of the Euro in 2013.

All costs related to each HPV-induced disease included in the study (Table 1) were adjusted for inflation in 2018 using the compound annual Italian National Consumer Price Indexes (NIC) provided by the Italian National Institute of Statistics (ISTAT).

\section{Incidence and HPV9 genotype attribution}

An estimate of the incident cases in the population over 18 years of age in Italy in 2018 [29] was obtained from the systematic literature review using the mean of the ranges provided by the selected studies. Crude incident rates per 100,000 residents in the 2018 resident Italian population [29] were calculated (Table 2). Due to the heterogeneity of the rates reviewed and the number of diseases involved, no standardization, meta-analyses or adjustments for the pyramidal stratification of the observed population were attempted. Due to a lack of Italian epidemiological data, the incidence of RPP was deliberately selected from the lower limit of the range cited in the literature [15].

Moreover, to estimate the costs attributable to HPV types $6,11,16,18,31,33,45,52$ and 58, prevalence rates of HPV DNA and genotype attribution per condition were identified from the systematic review. Specifically, for each condition, we first calculated the percentage of DNA attribution to exclude all cases that were not a result of HPV infection. We then applied prevalence rates from the literature to calculate the individual fractions attributable to genotypes included in HPV9 vaccine (Table 3 and Annexe A). These values were used to calculate the fraction of the total economic burden of HPV-induced malignancies attributable to the nine genotypes by both disease and sex according to the number of estimated incident cases. 
Table 2 Incidence rates, the prevalence of HPV, and HPV9 genotype fractions

\begin{tabular}{lccll}
\hline Diagnoses & $\begin{array}{l}\text { Incidence rates } \\
\text { (per 100,000) }\end{array}$ & HPV DNA+ (\%) & $\begin{array}{l}\text { HPV9 frac- } \\
\text { tion }(\%)\end{array}$ & Source \\
\hline Cervical cancer & 4.5 & 100.0 & 89.4 & {$[30-32]$} \\
Abnormal PAP smears & 699.2 & 100.0 & 91.5 & {$[15]$} \\
Colposcopies & 195.4 & 100.0 & 94.0 & {$[15]$} \\
Diagnosis of cervical dysplasia & 657.1 & 100.0 & 35.0 & {$[15]$} \\
CIN1 treatment & 35.9 & 100.0 & 75.0 & {$[15,32,33]$} \\
CIN2 treatment & 9.1 & 100.0 & 72.5 & {$[15,32,33]$} \\
CIN3 treatment & 10.0 & 100.0 & 57.2 & {$[15]$} \\
Anal cancer & 1.7 & 88.0 & 89.8 & {$[30,34]$} \\
Oropharyngeal cancer & 15.5 & 40.0 & 73.7 & {$[35,36]$} \\
Vulvar and vaginal cancer & 2.3 & 36.6 & 86.4 & {$[31]$} \\
Penile cancer & 0.8 & 50.0 & 81.6 & {$[30,37]$} \\
Anogenital warts & 241.6 & 100.0 & 90.0 & {$[15,34]$} \\
RRP & 0.4 & 100.0 & 95.0 & {$[38-40]$} \\
\hline
\end{tabular}

$C I N$ cervical intra-epithelial neoplasia, $R R P$ recurrent respiratory papillomatosis

\section{Statistical analyses}

Probabilistic and Deterministic Sensitivity Analyses (PSA and DSA) were developed to account for the variability of data used in the model. The PSA employed the differences found in the examined sources indicating minimum and maximum values of the uncertainty distribution for each parameter. The probabilistic distribution was prepared by applying normally reported values for the development of probabilistic models in economic evaluations, distinguishing between costs (gamma distribution) and epidemiological parameters (beta distribution) [41]. The distribution of each parameter was then used to perform 5000 Monte Carlo simulations to obtain interval estimates (95\% confidence interval (CI)) for the main epidemiological and economic data (Annex C).

The DSA was performed by adjusting each parameter to the highest and lowest possible values of the data obtained from the systematic review with a one-way approach. When a plausible range was not available from the literature, we assumed a variation of $10 \%$.

The critical parameters used to assess the uncertainty were: the number of incident cases per year, the HPV 6,11 , $16,18,31,33,45,52$ and 58, genotype attributions and cost parameters. We measured the impact of inserting the highest and lowest values for: (1) all diseases, (2) only oncologic diseases (defined as the sum of cervical, anal, oropharyngeal, vulvar, vaginal and penile cancers) (3) non-oncologic (cervical dysplasia, anogenital warts and RRP).

\section{Cost estimates of innovative therapeutic options not included in the DRG tariffs}

The DRG tariffs used as the main inputs for evaluating the direct costs of hospitalization did not include the costs of innovative therapeutic options that were added to the treatment guidelines for HPV-induced malignancies after 2013. The costs of these new drugs were actually debited to a National Account (named "File F"), which was specifically created to account for highly innovative therapeutic options. However, the administrative costs were paid for by the DRG tariff. File $\mathrm{F}$ is not accessible and does not provide information on the use of innovative drugs by indication. Therefore, identifying the resources allocated from File $\mathrm{F}$ used to treat HPV-induced malignancies is impossible. Ignoring these costs, however, would significantly underestimate the burden of HPV-induced diseases carried by the NHS. Therefore, we used the scenario analysis [42] method to estimate a range of credible costs for the innovative therapies used to treat HPV-induced malignancies. Following the latest guidelines of the Associazione Italiana di Oncologia Medica (AIOM) for the treatment of HPV-induced malignancies, two innovative therapeutic options were identified:

- Cetuximab (Erbitux), indicated for the treatment of head and neck cancer;

- Bevacizumab (Avastin), indicated for the treatment of recurrent or refractory cervical cancer.

The treatment and cost inputs used to determine the three scenarios are reported in Annex A.

\section{Results}

The annual incidence of the nine HPV-related conditions corresponded to approximately 1.1 million cases of which 975,000 associated to cervical conditions (86\%), and 158,000 to non-cervical (14\%). In 2018, the total direct 
costs (expressed relative to the 2018 Euro) associated with the annual incident cases of cervical cancer, cervical dysplasia, vulvar, vaginal, anus, penis and head and neck cancers, anogenital warts, and RRP in Italy were estimated to be $€ 542.7$ million, with a credible range of $€ 346.7-€ 782.0$ million. These costs could increase considering also the impact of innovative therapies for cancers treatment included in the scenario analysis with a plausible range between $€ 16.2$ and $€ 37.5$ million. The fraction attributable to the nine HPV9 genotypes included in our base case analysis, without considering the impact of innovative therapies, was $€ 329.5$ million (range $€ 157.0-€ 564.9$ million), accounting for approximately $61 \%$ of the total annual burden of HPV-related diseases in Italy.

\section{Cervical conditions}

The total cost estimate for cervical conditions was $€ 149.9$ million (range $€ 132.0-€ 168.9$ million), which corresponds to $28 \%$ of the total economic burden associated with
HPV-related diseases in Italy, (Table 3). Of this amount, $€ 69.7$ (range $€ 59.1-€ 81.2$ million) and $€ 80.2$ million (range $€ 66.2-€ 95.6$ million) were due to cervical cancer and total cervical dysplasia, respectively_estimates that include diagnosis, colposcopies, PAP smears and cervical neoplasia (CIN1/2/3). Additionally, the total annual cost associated with the management of cervical lesions, including the diagnosis and treatment of CIN1/2/3 stages, was $€ 54.0$ million (range $€ 41.0-€ 68.7$ million).

The fraction of cervical conditions attributable to HPV types $6,11,16,18,31,33,45,52$ and 58 was estimated to be $€ 118.3$ million (range $€ 104.2-€ 133.3$ million), $53 \%$ of which was related to cervical cancers ( $€ 62.3$ million, range $€ 52.6-€ 72.8)$.

\section{Non-cervical malignancies}

We evaluated the direct costs related to the treatment and follow-up of HPV-related cases of seven non-cervical

Table 3 Total lifetime costs and HPV-9 attributable fraction

$\begin{array}{ll}\text { Diagnoses } & \begin{array}{l}\text { Estimated number of incident cases } \\ \text { per year }\end{array}\end{array}$

Total lifetime direct costs per disease (mill Euro)

\begin{tabular}{|c|c|c|c|c|}
\hline $\mathrm{a}$ & Cervical cancer (CI 95\%) & $2698(2502-2902)$ & $€ 69.7(€ 59.1-€ 81.2)$ & $€ 62.3(€ 52.6-€ 72.8)$ \\
\hline $\mathrm{b}$ & Abnormal PAP smears (CI 95\%) & $422,922(345,068-507,585)$ & $€ 12.3(€ 9.1-€ 15.8)$ & $€ 11.2(€ 7.8-€ 15.1)$ \\
\hline $\mathrm{c}$ & Colposcopies (CI 95\%) & $118,214(95,649-142,480)$ & $€ 14.0(€ 10.3-€ 18.2)$ & $€ 13.1(€ 9.1-€ 17.8)$ \\
\hline $\mathrm{d}$ & $\begin{array}{l}\text { Diagnosis of cervical dysplasia (CI } \\
95 \%)\end{array}$ & $397,444(321,588-480,112)$ & $€ 15.9(€ 11.7-€ 20.6)$ & $€ 5.6(€ 3.8-€ 7.6)$ \\
\hline $\mathrm{e}$ & CIN1 treatment (CI 95\%) & $21,715(17,706-26,141)$ & $€ 17.5(€ 13-€ 22.6)$ & $€ 13.1(€ 9.3-€ 17.6)$ \\
\hline f & CIN2 treatment (CI 95\%) & $5532(1998-10,735)$ & $€ 8.0(€ 2.8-€ 16)$ & $€ 5.8(€ 1.9-€ 11.8)$ \\
\hline $\mathrm{g}$ & CIN3 treatment (CI 95\%) & $6047(2290-11,646)$ & $€ 12.6(€ 4.5-€ 24.6)$ & $€ 7.2(€ 2.5-€ 14.4)$ \\
\hline $\mathrm{h}$ & $\begin{array}{l}\text { Total cervical lesions }(d+e+f+g) \\
\quad(\text { CI } 95 \%)\end{array}$ & $430,738(35,4125-513,625)$ & $€ 54.0(€ 41-€ 68.7)$ & $€ 31.7(€ 23.3-€ 41.3)$ \\
\hline $\mathrm{i}$ & $\begin{array}{l}\text { Total cervical dysplasia }(b+c+h) \\
\quad(\text { CI } 95 \%)\end{array}$ & $971,874(857,453-1,090,683)$ & $€ 80.2(€ 66.2-€ 95.6)$ & $€ 56.0(€ 46-€ 67.1)$ \\
\hline 1 & $\begin{array}{l}\text { Total cervical conditions }(a+i)(\mathrm{CI} \\
95 \%)\end{array}$ & $974,572(860,140-1,093,375)$ & $€ 149.9(€ 132-€ 168.9)$ & $€ 118.3(€ 104.2-€ 133.3)$ \\
\hline $\mathrm{m}$ & Anal cancer (women) (CI 95\%) & $620(528-720)$ & $€ 7.2(€ 5.6-€ 8.9)$ & $€ 5.7(€ 4.3-€ 7.3)$ \\
\hline $\mathrm{n}$ & Anal cancer (men) (CI 95\%) & $437(360-522)$ & $€ 8.0(€ 6.1-€ 10.3)$ & $€ 6.4(€ 4.6-€ 8.4)$ \\
\hline o & $\begin{array}{l}\text { Oropharyngeal cancer (women) (CI } \\
95 \% \text { ) }\end{array}$ & $2200(2168-2232)$ & $€ 28.7(€ 23.6-€ 34.3)$ & $€ 8.4(€ 6.4-€ 10.8)$ \\
\hline $\mathrm{p}$ & $\begin{array}{l}\text { Oropharyngeal cancer (men) (CI } \\
95 \%)\end{array}$ & $7200(7184-7216)$ & $€ 187.0(€ 153.3-€ 224.1)$ & $€ 55.1(€ 41.2-€ 70.9)$ \\
\hline q & Vulvar and vaginal cancer (CI 95\%) & $1418(1275-1566)$ & $€ 18.3(€ 14.6-€ 22.3)$ & $€ 5.8(€ 4.4-€ 7.3)$ \\
\hline $\mathrm{r}$ & Penile cancer (CI 95\%) & $494(411-582)$ & $€ 4.2(€ 3.2-€ 5.3)$ & $€ 1.7(€ 1.3-€ 2.2)$ \\
\hline $\mathrm{s}$ & Anogenital warts (women) (CI 95\%) & $63,447(51,697-76,430)$ & $€ 44.6(€ 34.5-€ 56)$ & $€ 40.1(€ 28.5-€ 53.6)$ \\
\hline $\mathrm{t}$ & Anogenital warts (men) (CI 95\%) & $82,674(67,432-99,496)$ & $€ 41.2(€ 32.1-€ 51.5)$ & $€ 37.1(€ 26.4-€ 49.5)$ \\
\hline $\mathrm{u}$ & RRP (CI 95\%) & $249(0-1660)$ & $€ 53.6(€ 0-€ 372.8)$ & $€ 51.0(€ 0-€ 356)$ \\
\hline $\mathrm{v}$ & $\begin{array}{l}\text { Total non-cervical conditions }(m+n \\
+o+p+q+r+s+t+u)(\mathrm{CI} 95 \%)\end{array}$ & $158,739(139,079-179,749)$ & $€ 392.9(€ 206.3-€ 638.4)$ & $€ 211.2(€ 58.5-€ 460.1)$ \\
\hline $\mathrm{z}$ & Total burden $(l+v)(\mathrm{CI} 95 \%)$ & $1,133,312(1,016,911-1,253,343)$ & $€ 542.7(€ 346.7-€ 782)$ & $€ 329.5(€ 157-€ 564.9)$ \\
\hline
\end{tabular}

$C I N$ cervical intra-epithelial neoplasia, $R R P$ recurrent respiratory papillomatosis 
malignancies: cancer of the anus, oropharynx, vulva, vagina, and penis, anogenital warts and RPP. The economic burden associated with non-cervical conditions was $€ 392.9$ million, with a range of $€ 206.3-€ 638.4$ million. The amount corresponds to $72 \%$ of the total costs associated with HPV-related diseases in Italy. Oropharyngeal cancers were responsible for the highest annual burden of direct costs ( $€ 215.7$ million, $€ 187.0$ for men and $€ 28.7$ for women), followed by anogenital warts ( $€ 85.9$ million, $€ 41.2$ for men and $€ 44.6$ for women) and RPP ( $€ 53.6$ million). The costs related to all HPV-related diseases included in our study are reported in Table 3.

According to our systematic review, HPV virus were responsible for $36.6 \%$ of vulvar and vaginal cancers and $40 \%$ of oropharyngeal cancers, respectively, as well as $88 \%$ and $50 \%$ [30] of anal and penile cancers, respectively. The estimated fractions of the total annual direct costs attributable to HPV 6, 11, 16, 18, 31, 33, 45, 52 and 58-induced non-cervical malignancies were $€ 211.2$ million (range $€ 58.5-€ 460.1$ million), $61 \%$ of which was attributable to HPV 6 and 11 .

\section{Cost of innovative therapies not included in DRG tariffs}

Table 4 reports the outcomes of the scenario analysis. Three scenarios were obtained by varying the potential number of patients treated and the future availability of similar treatments at a reduced price. The credible range of the incremental costs allocated to innovative treatments of HPV-induced malignancies was $€ 16.2-€ 37.5$ million. This range represents a significant incremental cost compared to the DRG tariffs for the HPV-induced malignancies, ranging from 12.8 to $29.8 \%$.

The availability of similar therapies would reduce the incremental cost by approximately $22 \%$.

The fraction of HPV9-genotype costs attributable to men was equal to $€ 137.7$, while women accounted for $€ 194.4$. This corresponded to $58 \%$ of total costs attributable to HPV9 infections for women, whereas men accounted for $42 \%$. On the other hand, the economic burden of HPV 6, 11, 16, 18, $31,33,45,52$ and 58 infections that were related to noncervical conditions was higher for men than women (64.4\% vs $35.6 \%$ of the total, respectively) (Fig. 2).

The Tornado chart shown in Fig. 3 shows that the uncertainty in our evaluation of the economic burden of HPV9related diseases is mostly associated with the range of possible incidence rates for all groups of disease and costs.

\section{Discussion}

The purpose of this analysis was to estimate the economic burden of HPV-related diseases in Italy. Our study attempted to measure the direct costs from the real-world data perspective of the Italian National Health Service. The authors adopted a real-world data approach to estimate lifetime costs and conducted a systematic literature review to construct our estimation models with the most recent data available. Additionally, we included the nine HPV genotypes included in the new nine-valent vaccine that was made available in Europe in the last 2 years. Therefore, the present study is a first attempt to measure the economic burden of HPV-related diseases in Italy considering the newly available vaccine and data. By estimating the resource consumption attributable to the nine genotypes, we aim to predict the effects of both the 2017-2019 National Immunization Plan and the strategies recently adopted in Italy and to inform future public health decisions.

According to the results of this study, costs related to CIN1 treatment, vaginal cancer and cervical cancer were the most heavily influenced when including five HPV genotypes that accounted for $28 \%$ of their total cost on average. Furthermore, the economic burden among men represented more than one-third (42\%) of the total direct costs of HPV9 genotype-related diseases, including cervical conditions, which is consistent with previously published data $[6,15]$ and with the effort to extend the anti-HPV immunization programme to include boys in the National Immunization Plan 2017-2019.

The present study has several limitations. First, real-world data from administrative archives were only available for anal, head and neck, vulvar, vaginal and penile cancers, and published Italian sources of cost data were limited. Additionally, the quality of the available information was variable. Therefore, the use of different data sources may have diminished the comprehensiveness of our data. Specifically, the use of administrative data required certain assumptions to consistently estimate the lifetime costs from different data sources. Hospital discharge forms may have codification problems; therefore some information may be missing and/ or be wrongly reported. In this case, our analysis may have missed this information (due to the inclusion criteria), with the risk of underestimating the economic and epidemiological burden of the considered HPV-related diseases. Additionally, not all diseases led to hospitalization and this may be a further source of underestimation. Additionally, due to the scarcity of available data, we did not include drug utilization in our estimates. These limitations should be considered in future research; however, in our opinion, they do not undermine the validity of the cost estimates in the present study or their estimated impact on the total economic burden of HPV-related diseases. Future research should address these gaps in epidemiological and cost data to reduce the uncertainty associated with the present estimates. In conclusion, the present analysis is the first to provide a snapshot of the current state of resource utilization in Italy and the expected economic effects resulting from the 2017-2019 
Table 4 Credible range of incremental direct costs of the innovative therapies not included in DRG tariffs

\begin{tabular}{|c|c|c|c|c|c|}
\hline & $\begin{array}{l}\text { Base case: } \\
\text { (HPV9 } \\
\text { burden) }\end{array}$ & $\begin{array}{l}\text { Scenario 1: CRT } \\
\text { H\&N+bevacizumab } \\
\text { recurrent CC }\end{array}$ & $\begin{array}{l}\text { Scenario 2: CRT + CCT in } \\
\mathrm{H} \& \mathrm{~N}+\text { bevacizumab for } \\
\text { recurrent and metastatic CC }\end{array}$ & $\begin{array}{l}\text { Scenario } 3:=\text { Scenario } 2 \text { but } \\
\text { biosimilars available }(25 \% \\
\text { off })\end{array}$ & Source \\
\hline \multicolumn{6}{|c|}{ Base case-oropharyngeal cancer } \\
\hline $\begin{array}{l}\text { Incident patients infected by } \\
\text { HPV9-susceptible strains }\end{array}$ & 2771 & 2771 & 2771 & 2771 & \\
\hline Cost/patient & $€ 22,980$ & $€ 22,980$ & $€ 22,980$ & $€ 22,980$ & \\
\hline Total cost (Euro mill) & $€ 63.7$ & $€ 63.7$ & $€ 63.7$ & $€ 63.7$ & \\
\hline \multicolumn{6}{|l|}{ Incremental cetuximab scenarios } \\
\hline $\begin{array}{l}\text { Cetuximab }+ \text { RT in } \\
\text { patients }>70 \text { years }(28 \% \\
\text { of total eligible })\end{array}$ & & 776 & 776 & 776 & \\
\hline $\begin{array}{l}\text { Incremental cost of Cetuxi- } \\
\text { mab added to RT/patient }\end{array}$ & & $€ 8133$ & $€ 8133$ & $€ 6133$ & [43] \\
\hline $\begin{array}{l}\text { Total incremental cost } \\
\text { (Euro mill) }\end{array}$ & & $€ 6.3$ & $€ 6.3$ & $€ 4.8$ & \\
\hline $\begin{array}{l}\text { Cetuximab }+ \text { CT in Stage } \\
\text { III-IV patients in good } \\
\text { performance condition } \\
(80 \%)\end{array}$ & & & $€ 443.4$ & $€ 443.4$ & \\
\hline $\begin{array}{l}\text { Incremental cost of cetuxi- } \\
\text { mab added to CT/patient }\end{array}$ & & & $€ 5201.0$ & $€ 3907.3$ & [43] \\
\hline $\begin{array}{l}\text { Total incremental cost } \\
\text { (Euro mill) }\end{array}$ & & & $€ 2.3$ & $€ 1.7$ & \\
\hline \multicolumn{6}{|l|}{ Base case-cervical cancer } \\
\hline $\begin{array}{l}\text { Incident patients infected by } \\
\text { HPV9-susceptible strains }\end{array}$ & 2412 & 2412 & 2412 & 2412 & \\
\hline Treatment cost/patient & $€ 25,790$ & $€ 25,790$ & $€ 25,790$ & $€ 25,790$ & \\
\hline Total cost (Euro mill) & $€ 62$ & $€ 62$ & $€ 62$ & $€ 62$ & \\
\hline \multicolumn{6}{|c|}{ Incremental bevacizumab scenarios } \\
\hline $\begin{array}{l}\text { Incident cervical patients } \\
\text { HPV9 + and VEGF+ } \\
\text { (60\% of incident) }\end{array}$ & & $€ 1447$ & $€ 1447$ & $€ 1447$ & [44] \\
\hline $\begin{array}{l}\text { Recurrent patients ( } 31 \% \text { of } \\
\text { incident VEGF+) }\end{array}$ & & $€ 449$ & $€ 449$ & $€ 449$ & {$[45]$} \\
\hline $\begin{array}{l}\text { Incremental cost of bevaci- } \\
\text { zumab added to CT }\end{array}$ & & $€ 21,966$ & $€ 21,966$ & $€ 16,475$ & \\
\hline $\begin{array}{l}\text { Total incremental cost } \\
\text { (Euro mill) }\end{array}$ & & $€ 10$ & $€ 10$ & $€ 7$ & \\
\hline $\begin{array}{l}\text { Metastatic patients ( } 60 \% \text { of } \\
\text { incident VEGF+) }\end{array}$ & & & $€ 868$ & $€ 868$ & [45] \\
\hline $\begin{array}{l}\text { Incremental cost of bevaci- } \\
\text { zumab added to CT }\end{array}$ & & & $€ 21,966$ & $€ 16,475$ & {$[46]$} \\
\hline $\begin{array}{l}\text { Total incremental cost } \\
\text { (Euro mill) }\end{array}$ & & & $€ 19.07$ & $€ 14.31$ & \\
\hline \multicolumn{6}{|c|}{ Total treatment cost per scenario (Euro mill) } \\
\hline $\begin{array}{l}\text { Incremental cost vs base } \\
\text { case (Euro mill) }\end{array}$ & $€ 125.9$ & $€ 142.1$ & $€ 163.4$ & $€ 154.1$ & \\
\hline $\begin{array}{l}\text { Incremental cost as a \% of } \\
\text { base case }\end{array}$ & & $€ 16.2$ & $€ 37.5$ & $€ 28.2$ & \\
\hline
\end{tabular}

$O P C$ oropharyngeal cancer, $C$ cetuximab, $R T$ radiation therapy, $C T$ chemotherapy, $V E G F$ vascular endothelial growth factor, $C C$ cervical cancer 
Fig. 2 Fractions of HPV 9 costs by gender. $R R P$ recurrent respiratory papillomatosis
Fig. 3 Deterministic sensitivity analysis (DSA). Oncologic: cervical, anal, oropharyngeal, vulvar, vaginal and penile cancers

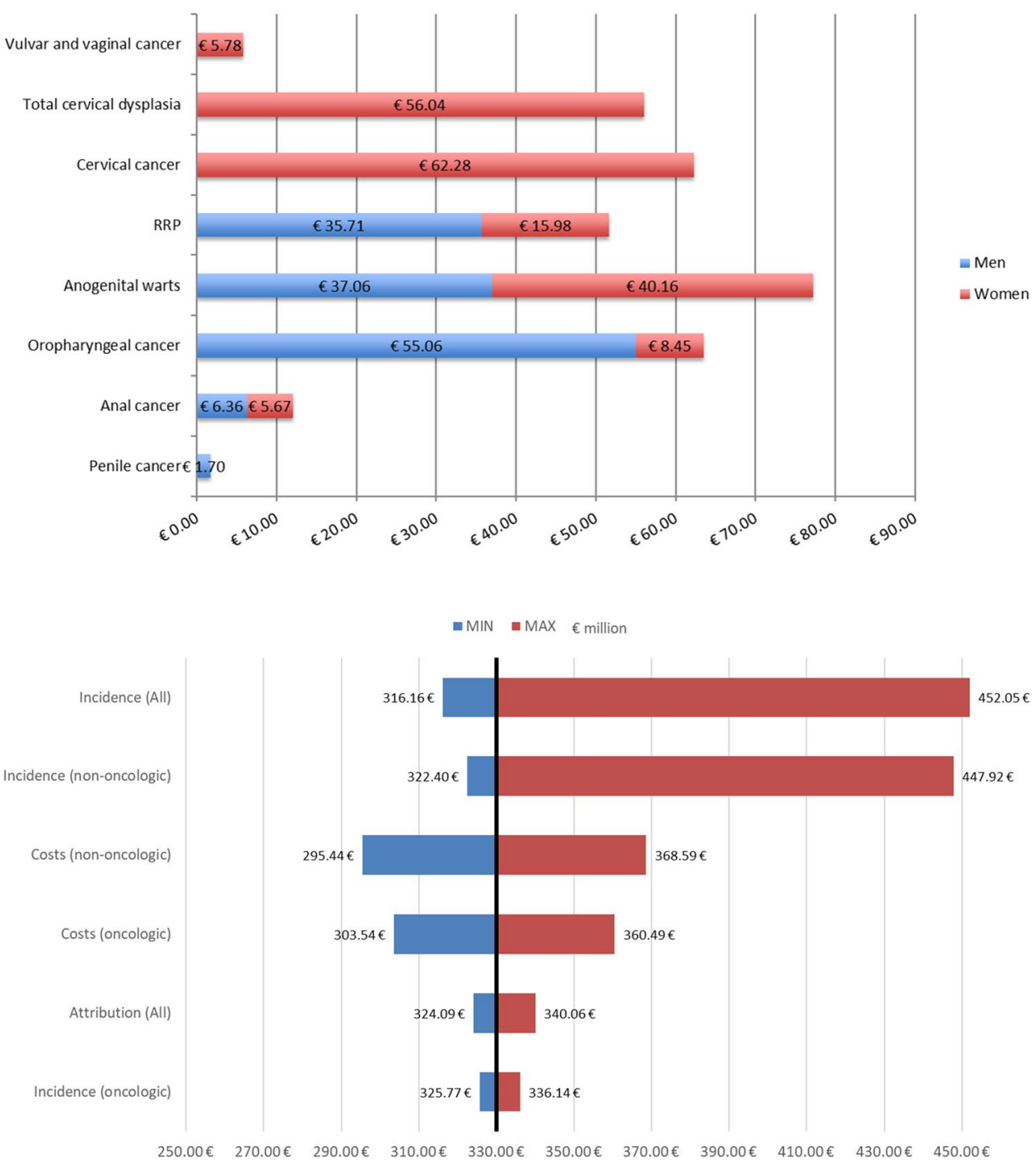

National Immunization Plan. Therefore, we believe that this analysis may provide a tool for keeping records of the expected economic effects over time.

Funding The study was supported with unrestricted funding from MSD Italy.

\section{Compliance with ethical standards}

Conflict of interest The authors declare that they have no conflict of interest.

\section{References}

1. Goldstone, S., et al.: Prevalence of and risk factors for human papillomavirus (HPV) infection among HIV-seronegative men who have sex with men. J. Infect. Dis. 203(1), 66-74 (2011)
2. McQuillan, G.M., et al.: Prevalence of HPV in adults aged 18-69: United States, 2011-2014. US Department of Health and Human Services, Centers for Disease Control and Prevention, National Center for Health Statistics, Hyattsville, MD (2017)

3. Favato, G., et al.: A novel method to value real options in health care: the case of a multicohort human papillomavirus vaccination strategy. Clin. Ther. 35(7), 904-914 (2013)

4. Clifford, G.M., et al.: Human papillomavirus types in invasive cervical cancer worldwide: a meta-analysis. Br. J. Cancer 88(1), 63-73 (2003)

5. Walboomers, J.M., et al.: Human papillomavirus is a necessary cause of invasive cervical cancer worldwide. J. Pathol. 189(1), 12-19 (1999)

6. Chaturvedi, A.K.: Beyond cervical cancer: burden of other HPVrelated cancers among men and women. J. Adolesc. Health 46(4 Suppl), S20-S26 (2010)

7. Koutsky, L.A., Galloway, D.A., Holmes, K.K.: Epidemiology of genital human papillomavirus infection. Epidemiol. Rev. 10, 122$163(1988)$

8. Armstrong, L.R., Derkay, C.S., Reeves, W.C.: Initial results from the national registry for juvenile-onset recurrent respiratory papillomatosis. RRP Task Force. Arch. Otolaryngol. Head Neck Surg. 125(7), 743-748 (1999) 
9. Armstrong, L.R., et al.: Incidence and prevalence of recurrent respiratory papillomatosis among children in Atlanta and Seattle. Clin. Infect. Dis. 31(1), 107-109 (2000)

10. Hartwig, S., Baldauf, J.J., Dominiak-Felden, G.: Estimation of the epidemiological burden of HPV-related cancers, precancerous lesions, and genital warts in women and men in Europe: potential additional benefit of a nine-valent compared to first generation HPV vaccines. Papillomavirus Res 1, 90-100 (2015)

11. FDA approves Gardasil 9 for prevention of certain cancers caused by five additional types of HPV. 12/11/2014, 12 Aug 2015. http:// www.fda.gov/NewsEvents/Newsroom/PressAnnouncements/ucm42 6485.htm (2014)

12. Jit, M., Choi, Y.H., Edmunds, W.J.: Economic evaluation of human papillomavirus vaccination in the United Kingdom. BMJ 337, a769 (2008)

13. Kim, J.J., Goldie, S.J.: Health and economic implications of HPV vaccination in the United States. N. Engl. J. Med. 359(8), 821-832 (2008)

14. Favato, G., et al.: Novel health economic evaluation of a vaccination strategy to prevent HPV-related diseases: the BEST study. Med. Care 50(12), 1076-1085 (2012)

15. Baio, G., et al.: Economic burden of human papillomavirus-related diseases in Italy. PLoS One 7(11), e49699 (2012)

16. Ministero della Salute: Piano Nazionale Prevenzione Vaccinale 2017-2019. http://www.salute.gov.it/portale/documentazione/ p6_2_2_1.jsp?id=2571

17. Ferrandina, G., et al.: Hospital costs incurred by the Italian National Health Service for invasive cervical cancer. Gynecol. Oncol. 119(2), 243-249 (2010)

18. Mennini, F.S., et al.: Anti-HPV vaccination: a review of recent economic data for Italy. Vaccine 27(Suppl 1), A54-A61 (2009)

19. Giorgi Rossi, P., et al.: Epidemiology and costs of cervical cancer screening and cervical dysplasia in Italy. BMC Public Health 9, 71 (2009)

20. Mennini, F.S., et al.: Health and economic impact associated with a quadrivalent HPV vaccine in Italy. Gynecol. Oncol. 112(2), 370-376 (2009)

21. Salute, M.: Remunerazione prestazioni di assistenza ospedaliera per acuti, assistenza ospedaliera di raibilitazione e di lungodegenza post acuzie e di assistenza specialistica ambulatoriale. 2013, Pubblicato sulla GURI N. 23 del 28/01/2013 Suppl. n. 8

22. Merito, M., et al.: Treatment patterns and associated costs for genital warts in Italy. Curr. Med. Res. Opin. 24(11), 3175-3183 (2008)

23. Istat: https://rivaluta.istat.it (2018). Accessed Jan 2019

24. Mennini, F.S., et al.: Burden of disease of human papillomavirus (HPV): hospitalizations in the Marche and Veneto regions. An observational study. Clin. Drug Investig. 38(2), 173-180 (2018)

25. Moher, D., et al.: Preferred reporting items for systematic reviews and meta-analyses: the PRISMA statement. PLoS Med. 6(7), e1000097 (2009)

26. Fattore, G.: Proposta di linee guida per la valutazione economica degli interventi sanitari in Italia. PharmacoEcon. Ital. Res. Artic. 11(2), 83-93 (2009)

27. Bishai, D., Kashima, H., Shah, K.: The cost of juvenile-onset recurrent respiratory papillomatosis. Arch. Otolaryngol. Head Neck Surg. 126(8), 935-939 (2000)

28. Hu, D., Goldie, S.: The economic burden of noncervical human papillomavirus disease in the United States. Am. J. Obstet. Gynecol. 198(5), 500e1-500e7 (2008)
29. Istituto Nazionale di Statistica (ISTAT): Popolazione residente al 1 Gennaio 2018. Statistiche Demografiche (2018). http://demo.istat .it/. Accessed Jan 2019

30. AIOM, A.: I numeri del cancro in Italia 2017. I.P.S. Editore, Editor (2017)

31. Serrano, B., et al.: Human papillomavirus genotype attribution for HPVs 6, 11, 16, 18, 31, 33, 45, 52 and 58 in female anogenital lesions. Eur. J. Cancer 51(13), 1732-1741 (2015)

32. WHO, I., Information Centre on HPV and Cervical Cancer (HPV Information Centre). Human papillomavirus and related cancers in Italy, I. Summary Report, Editor (2017)

33. Garcia-Espinosa, B., Moro-Rodriguez, E., Alvarez-Fernandez, E.: Genotype distribution of human papillomavirus (HPV) in histological sections of cervical intraepithelial neoplasia and invasive cervical carcinoma in Madrid, Spain. BMC Cancer 12, 533 (2012)

34. Hartwig, S., et al.: Estimation of the epidemiological burden of human papillomavirus-related cancers and non-malignant diseases in men in Europe: a review. BMC Cancer 12, 30 (2012)

35. Abogunrin, S., et al.: Prevalence of human papillomavirus in head and neck cancers in European populations: a meta-analysis. BMC Cancer 14, 968 (2014)

36. Castellsague, X., et al.: HPV involvement in head and neck cancers: comprehensive assessment of biomarkers in 3680 patients. J. Natl. Cancer Inst. 108(6), djv403 (2016)

37. Miralles-Guri, C., et al.: HPV prevalence and type distribution in penile carcinoma. J. Clin. Pathol. 62(10), 870-878 (2009)

38. Donne, A.J., et al.: The role of HPV type in Recurrent Respiratory Papillomatosis. Int. J. Pediatr. Otorhinolaryngol. 74(1), 7-14 (2010)

39. Fusconi, M., et al.: Recurrent respiratory papillomatosis by HPV: review of the literature and update on the use of cidofovir. Acta Otorhinolaryngol. Ital. 34(6), 375-381 (2014)

40. Lacey, C.J., Lowndes, C.M., Shah, K.V.: Chap. 4: Burden and management of non-cancerous HPV-related conditions: HPV-6/11 disease. Vaccine 24(Suppl 3), S3/35-S41 (2006)

41. Briggs, A.H., Claxton, K., Sculpher, M.J.: Decision modelling for health economic evaluation. Handbooks in health economic evaluation series. Oxford University Press, Oxford (2006) (x, 237, ill.; 24 cm)

42. Favato, G., Vecchiato, R.: Embedding real options in scenario planning: a new methodological approach. Technol. Forecast. Soc. Change 124(November 2017), 135-149 (2017)

43. Brown, B., et al.: An economic evaluation of cetuximab combined with radiotherapy for patients with locally advanced head and neck cancer in Belgium, France, Italy, Switzerland, and the United Kingdom. Value Health 11(5), 791-799 (2008)

44. Mandic, A., Usaj Knezevic, S., Kapicl, T., Ivkovic: Tissue expression of VEGF in cervical intraepithelial neoplasia and cervical cancer. J BUON 19(4), 958-964 (2014)

45. Friedlander, M., Grogan, M., Force, U.S.P.S.T.: Guidelines for the treatment of recurrent and metastatic cervical cancer. Oncologist 7(4), 342-347 (2002)

46. Tewari, K.S., et al.: Bevacizumab for advanced cervical cancer: final overall survival and adverse event analysis of a randomised, controlled, open-label, phase 3 trial (Gynecologic Oncology Group 240). Lancet 390(10103), 1654-1663 (2017)

Publisher's Note Springer Nature remains neutral with regard to jurisdictional claims in published maps and institutional affiliations. 